Review

\title{
Function and Regulation of Ferredoxins in the Cyanobacterium, Synechocystis PCC6803: Recent Advances
}

\section{Corinne Cassier-Chauvat * and Franck Chauvat}

UMR8221, CEA, CNRS, Université Paris-Sud, Institut de Biologie et Technologie Saclay, Laboratoire de Biologie et Biotechnologie des Cyanobactéries, CEA-Saclay,

Gif sur Yvette 91190, France; E-Mail: franck.chauvat@cea.fr

* Author to whom correspondence should be addressed; E-Mail: corinne.cassier-chauvat@cea.fr; Tel.: +33-1-69-08-35-74.

External Editors: John C. Meeks and Robert Haselkorn

Received: 9 September 2014; in revised form: 24 October 2014 / Accepted: 27 October 2014 / Published: 7 November 2014

\begin{abstract}
Ferredoxins (Fed), occurring in most organisms, are small proteins that use their iron-sulfur cluster to distribute electrons to various metabolic pathways, likely including hydrogen production. Here, we summarize the current knowledge on ferredoxins in cyanobacteria, the prokaryotes regarded as important producers of the oxygenic atmosphere and biomass for the food chain, as well as promising cell factories for biofuel production. Most studies of ferredoxins were performed in the model strain, Synechocystis PCC6803, which possesses nine highly-conserved ferredoxins encoded by monocistronic or operonic genes, some of which are localized in conserved genome regions. Fed1, encoded by a light-inducible gene, is a highly abundant protein essential to photosynthesis. Fed2-Fed9, encoded by genes differently regulated by trophic conditions, are low-abundant proteins that play prominent roles in the tolerance to environmental stresses. Concerning the selectivity/redundancy of ferredoxin, we report that Fed1, Fed7 and Fed9 belong to ferredoxin-glutaredoxin-thioredoxin crosstalk pathways operating in the protection against oxidative and metal stresses. Furthermore, Fed7 specifically interacts with a DnaJ-like protein, an interaction that has been conserved in photosynthetic eukaryotes in the form of a composite protein comprising DnaJ- and Fed7-like domains. Fed9 specifically interacts with the Flv3 flavodiiron protein acting in the photoreduction of $\mathrm{O}_{2}$ to $\mathrm{H}_{2} \mathrm{O}$.
\end{abstract}


Keywords: cyanobacteria; ferredoxins; iron-sulfur cluster; electron transfer; oxidative stress; metal stress; regulation

\section{Introduction}

Ferredoxins (Fed) are small, mostly acidic, soluble proteins found ubiquitously in biological organisms. They possess a highly negative redox potential and use their iron-sulfur cluster to act as electron distributors in various metabolic pathways. The Fed proteins can be classified according to the nature of their iron-sulfur center $([2 \mathrm{Fe}-2 \mathrm{~S}],[3 \mathrm{Fe}-4 \mathrm{~S}]$ and $[4 \mathrm{Fe}-4 \mathrm{~S}])$ and the organisms in which they were isolated for the first time [1]. Hence, the ferredoxins with a [2Fe-2S] cluster can be divided into plant-type or bacterial-type Feds. In plants, algae and cyanobacteria, i.e., prokaryotes with a plant-like oxygen-evolving photosynthetic apparatus, the most abundant ferredoxin, the plant-type [2Fe-2S] Fed, designated as Fed1, is recognized primarily as the protein that mediates electron transfer from iron-sulfur centers of photosystem I (PSI-C subunit) to ferredoxin NADP reductase, which, in turn, reduces $\mathrm{NADP}^{+}$for $\mathrm{CO}_{2}$ fixation [2]. Fed1 is also involved in other redox processes, such as cyclic photophosphorylation, nitrogen assimilation, biosynthesis of glutamate and chlorophyll, sulfite reduction, fatty acid metabolism and the modulation of the activity of various enzymes via the thioredoxin system [2]. Furthermore, a Fed1-like domain containing bacteriocin, named "peptocin M2", was recently shown to parasitize the cell entry and Fed-dependent iron acquisition system of the plant pathogens, Pectobacterium spp. [3].

Like other photosynthetic organisms, cyanobacteria possess various [2Fe-2S] and [4Fe-4S] Feds that have received less attention than Fed1, so far [2]. The interest in these ferredoxins has increased by the recent in vitro indications that one of these Fed can directly reduce NiFe-hydrogenase, which can produce hydrogen in some conditions [4]. In this review, we summarize what is known about the function and regulation of ferredoxins in cyanobacteria, emphasizing the unicellular model cyanobacterium, Synechocystis PCC6803, where the Fed proteins have been mostly studied.

\section{The Nine Ferredoxins of Synechocystis Are Highly Conserved in Cyanobacteria}

Synechocystis (hereafter Synechocystis) possesses a small sequenced genome [5], easily manipulable [6-8], which encodes nine Feds representative of the ferredoxin diversity. The fed $1-6$ genes encode [2Fe-2S] ferredoxins; fed7 encodes a [4Fe-4S] protein; fed 8 encodes a [3Fe-4S] [4Fe-4S] Fed; and $f e d 9$ encodes a [4Fe-4S] [4Fe-4S] ferredoxin. In agreement with the pivotal role of Feds in electron transfer, all nine Synechocystis fed-encoding genes appeared to be highly conserved in cyanobacteria (Table 1). Furthermore a large number of the $f e d$ genes belong to well-conserved gene clusters (Figure 1), indicating that they operate in specific conserved functions relating to cyanobacterial life. 
Table 1. Distribution of ferredoxin-encoding genes in cyanobacteria.

\begin{tabular}{|c|c|c|c|c|c|c|c|c|c|c|}
\hline \multirow{4}{*}{ Cyanobacterial Species } & \multicolumn{10}{|c|}{ Occurrence of Ferredoxin-Encoding Genes } \\
\hline & \multicolumn{7}{|c|}{$[2 \mathrm{Fe}-2 \mathrm{~S}]$} & \multicolumn{3}{|c|}{$[3 \mathrm{Fe}-4 \mathrm{~S}]$ and $[4 \mathrm{Fe}-4 \mathrm{~S}]$} \\
\hline & \multicolumn{5}{|c|}{ Plant-like } & \multicolumn{2}{|c|}{ Bacterial-type } & \multirow[b]{2}{*}{ fed 7} & \multirow[b]{2}{*}{ feds } & \multirow[b]{2}{*}{ fed 9} \\
\hline & $\sum$ & fed1 & fed2 & fed3 & fed4 & fed5 & fed6 & & & \\
\hline Gloeobacter kilaueensis JS1 & 3 & + & + & - & - & - & - & $+\mathrm{g}$ & + & + \\
\hline Gloeobacter violaceus PCC7421 & 2 & + & + & - & - & - & - & $+\mathrm{g}$ & + & + \\
\hline Anabaena cylindrica PCC7122 & 5 & $+{ }^{\mathrm{a}}$ & $+c$ & $+{ }^{d}$ & - & - & + & $+\mathrm{g}$ & $+\mathrm{h}$ & $+\mathrm{j} *$ \\
\hline Anabaena sp. 90 & 4 & + & + & $+{ }^{d}$ & - & - & - & $+\mathrm{g}$ & $+\mathrm{h}^{\prime}$ & $+{ }^{j} *$ \\
\hline Anabaena variabilis ATCC29413 & 6 & $+{ }^{a}$ & $+c$ & $+{ }^{d}$ & - & - & - & $+\mathrm{g}$ & $+{ }^{h}$ & $+\mathrm{j}$ \\
\hline Cylindrospermum stagnale PCC7417 & 6 & $+{ }^{a}$ & $++^{c}$ & $+{ }^{d}$ & - & - & $+{ }^{f^{\prime}}$ & $+\mathrm{g}$ & $+{ }^{h}$ & $++^{\mathrm{j}}$ \\
\hline Nostoc punctiforme PCC73102 & 6 & $2^{\mathrm{a}}$ & + & $+{ }^{d}$ & - & - & $2 / 1^{f^{\prime}}$ & $+\mathrm{g}$ & $+\mathrm{h}$ & + \\
\hline Nostoc sp. PCC7107 & 4 & $+{ }^{a}$ & + & $+{ }^{d}$ & - & - & - & $+\mathrm{g}$ & $+\mathrm{h}^{\prime}$ & $+\mathrm{j}$ \\
\hline Nostoc sp. PCC7120 & 4 & $+{ }^{\mathrm{a}}$ & $+c$ & $+d$ & - & - & + & $+\mathrm{g}$ & $+\mathrm{h}$ & $++^{\mathrm{j}}$ \\
\hline Nostoc sp. PCC7524 & 4 & $+{ }^{a}$ & $++^{c}$ & $+\mathrm{d}^{\prime}$ & - & - & $+\mathrm{f}^{\prime}$ & $+\mathrm{g}$ & $+{ }^{h}$ & + \\
\hline Nostoc azollae 0708 & 5 & $+{ }^{a}$ & $+c$ & $+{ }^{d}$ & - & - & + & $+\mathrm{g}$ & $+{ }^{h}$ & $+\mathrm{j} *$ \\
\hline Calothrix sp. PCC6303 & 4 & $+a^{\prime}$ & + & + & - & - & + & $+\mathrm{g}$ & $+\mathrm{h}^{\prime \prime}$ & + \\
\hline Calothrix sp. PCC7507 & 6 & $2^{a}$ & + & $+{ }^{d}$ & - & - & + & $+\mathrm{g}$ & + & $+\mathrm{j}$ \\
\hline Rivularia sp. PCC7116 & 6 & $2^{a^{\prime}}$ & $+^{\mathrm{c}}$ & + & - & - & $+{ }^{\mathrm{f}}$ & $+\mathrm{g}$ & + & $+\mathrm{j}^{\prime \prime}$ \\
\hline Acaryochloris marina MBIC11017 & 8 & 3 & $+c$ & + & - & $5 / 3$ e* & - & $+\mathrm{g}$ & $+{ }^{\mathrm{i}}$ & + \\
\hline Chamaesiphon minutus РCC6605 & 5 & $+a^{\prime}$ & + & + & - & + & - & $+\mathrm{g}$ & + & + \\
\hline Cyanobacterium aponinum PC 10605 & 4 & $+a^{\prime}$ & + & + & - & $+\mathrm{e} *$ & $+{ }^{\mathrm{f}}$ & $+\mathrm{g}$ & $+{ }^{\mathrm{i}}$ & + \\
\hline Cyanobacterium stanieri PCC7202 & 4 & + & + & + & - & $-\mathrm{e} *$ & - & $+\mathrm{g}$ & $+{ }^{\mathrm{i}}$ & $+\mathrm{j}^{\prime \prime}$ \\
\hline Cyanobium gracile PCC6307 & 4 & + & + & + & - & - & - & $+\mathrm{g}$ & $+{ }^{h}$ & $+\mathrm{j}^{\prime \prime}$ \\
\hline Cyanothece sp. ATCC51142 & 7 & $2^{a^{\prime}}$ & + & + & $+e$ & $+e$ & - & $+\mathrm{g}$ & $++^{i}$ & $+\mathrm{j}^{\prime \prime}$ \\
\hline Cyanothece sp. PCC7424 & 5 & $+a^{\prime}$ & + & + & $+^{e}$ & $+{ }^{e}$ & - & $+\mathrm{g}$ & $+{ }^{\mathrm{i}}$ & $+\mathrm{j}^{\prime \prime}$ \\
\hline Cyanothece sp. PCC7425 & 5 & + & $+c^{\prime}$ & + & - & $+\mathrm{e} *$ & - & $+\mathrm{g}$ & + & + \\
\hline Cyanothece sp. PCC7822 & 7 & $2^{a^{\prime}}$ & $+\mathrm{c}^{\prime}$ & + & $+{ }^{e}$ & $+{ }^{e}$ & - & $+\mathrm{g}$ & $+{ }^{\mathrm{i}}$ & + \\
\hline Cyanothece sp. PCC8801 & 5 & + & $+\mathrm{c}^{\prime \prime}$ & + & $+^{\mathrm{e}}$ & $+{ }^{e}$ & - & $+\mathrm{g}$ & $+{ }^{\mathrm{i}}$ & $+\mathrm{j}^{\prime \prime}$ \\
\hline Cyanothece sp. PCC8802 & 5 & + & $+\mathrm{c}^{\prime \prime}$ & + & $++^{e}$ & $+{ }^{e}$ & - & $+\mathrm{g}$ & $+{ }^{\mathrm{i}}$ & $+\mathrm{j}^{\prime \prime}$ \\
\hline Dactylococcopsis salina PCC8305 & 3 & + & + & + & - & - & - & $+\mathrm{g}$ & $+{ }^{\mathrm{i}}$ & + \\
\hline Gloeocapsa sp. PCC7428 & 7 & $+a^{\prime}$ & + & + & - & $+\mathrm{e} *$ & - & $+\mathrm{g}$ & + & $+\mathrm{j}^{\prime \prime}$ \\
\hline Halothece sp. PCC7418 & 4 & + & + & + & - & - & - & $+\mathrm{g}$ & $+{ }^{\mathrm{i}}$ & $+\mathrm{j}^{\prime \prime}$ \\
\hline Microcystis aeruginosa NIES-843 & 4 & 2 & $+\mathrm{c}^{\mathrm{n}}$ & + & - & - & - & $+\mathrm{g}$ & + & $+\mathrm{j}^{\prime \prime}$ \\
\hline Synechococcus elongatus PCC6301 & 3 & $+{ }^{b}$ & + & + & - & - & - & $+\mathrm{g}$ & + & $+\mathrm{j}^{\prime \prime}$ \\
\hline Synechococcus elongatus PCC7942 & 3 & $+{ }^{b}$ & + & $+{ }^{d}$ & - & - & - & $+\mathrm{g}$ & + & $+\mathrm{j}^{\prime \prime}$ \\
\hline Synechococcus sp. CC9311 & 6 & $2^{b}$ & + & $+{ }^{d}$ & - & - & - & $+\mathrm{g}$ & + & - \\
\hline Synechococcus sp. CC9605 & 6 & $+{ }^{b}$ & + & $+{ }^{d}$ & - & - & - & $2^{g}$ & + & - \\
\hline Synechococcus sp. CC9902 & 5 & $+{ }^{b}$ & + & $+{ }^{d}$ & - & - & - & $+\mathrm{g}$ & + & - \\
\hline Synechococcus $J A-2-3 B^{\prime}$ a(2-13) & 4 & + & + & + & - & 2 & - & - & + & + \\
\hline Synechococcus $J A-3-3 B^{\prime} A b$ & 4 & + & + & + & - & 2 & - & - & + & + \\
\hline Synechococcus sp. PCC 6312 & 4 & + & + & $+{ }^{d}$ & - & $+\mathrm{e}^{*}$ & - & $+\mathrm{g}$ & + & + \\
\hline Synechococcus sp. PCC7002 & 4 & $2^{a^{\prime}}$ & + & + & - & 2 & - & $+\mathrm{g}$ & + & + \\
\hline Synechococcus sp. PCC7502 & 4 & + & + & + & - & 3 & - & $+\mathrm{g}$ & + & + \\
\hline Synechococcus sp. RCC307 & 4 & $+{ }^{b}$ & $+\mathrm{c}^{\prime \prime}$ & $+{ }^{d}$ & - & - & - & $+\mathrm{g}$ & + & $+\mathrm{j}^{\prime \prime}$ \\
\hline Synechococcus sp. WH7803 & 4 & $+{ }^{b}$ & $+\mathrm{c}^{\mathrm{\prime \prime \prime}}$ & $+{ }^{\mathrm{d}}$ & - & - & - & $+\mathrm{g}$ & + & - \\
\hline
\end{tabular}


Table 1. Cont.

\begin{tabular}{|c|c|c|c|c|c|c|c|c|c|c|}
\hline \multirow{4}{*}{ Cyanobacterial Species } & \multicolumn{10}{|c|}{ Occurrence of Ferredoxin-Encoding Genes } \\
\hline & \multicolumn{7}{|c|}{$[2 \mathrm{Fe}-2 \mathrm{~S}]$} & \multicolumn{3}{|c|}{$[3 \mathrm{Fe}-4 \mathrm{~S}]$ and $[4 \mathrm{Fe}-4 \mathrm{~S}]$} \\
\hline & \multicolumn{5}{|c|}{ Plant-like } & \multicolumn{2}{|c|}{ Bacterial-type } & \multirow[b]{2}{*}{ fed 7} & \multirow[b]{2}{*}{ fed8 } & \multirow[b]{2}{*}{ fed 9} \\
\hline & $\sum$ & fed1 & fed2 & fed3 & fed4 & fed5 & fed6 & & & \\
\hline Synechococcus sp. WH8102 & 4 & $+\mathrm{b}$ & $+\mathrm{c}^{\mathrm{c} " \mathrm{\prime}}$ & $+{ }^{d}$ & - & - & - & $+\mathrm{g}$ & + & - \\
\hline Synechocystis sp. PCC6803 & 4 & + & $+\mathrm{c}^{\prime \prime}$ & + & $+e^{\prime}$ & $+e^{\prime}$ & $+\mathrm{f}^{*}$ & $+\mathrm{g}$ & $+\mathrm{i}$ & + \\
\hline Thermosynechococcus elongatus BPI & 4 & + & + & + & - & $+\mathrm{e}^{\mathrm{n}}$ & - & $+\mathrm{g}$ & + & + \\
\hline Cyanobacterium UCYN-A & 4 & + & + & + & - & - & - & - & + & - \\
\hline Arthrospira platensis NIES-39 & 3 & + & $+{ }^{c}$ & $+d$ & - & + & - & $+\mathrm{g}$ & + & $+\mathrm{j}^{\prime \prime}$ \\
\hline Crinalium epipsammum РСС9333 & 4 & $+\mathrm{a}^{\mathrm{a}}$ & $++^{\mathrm{c}}$ & $+d$ & - & - & $+{ }^{f}$ & $+\mathrm{g}$ & + & $+\mathrm{j}^{\prime \prime}$ \\
\hline Geitlerinema sp. PCC7407 & 3 & $+\mathrm{a}^{\mathrm{a}}$ & $+{ }^{c}$ & $+d$ & - & + & $+f$ & $+\mathrm{g}$ & + & + \\
\hline Leptolyngbya sp. PCC7376 & 4 & $2^{\mathrm{a} "}$ & $+{ }^{c}$ & + & - & + & - & - & + & + \\
\hline Microcoleus sp. PCC7113 & 6 & 2 & $+{ }^{c}$ & + & - & - & $+^{\mathrm{f}}$ & $+\mathrm{g}$ & + & $+\mathrm{j}^{\prime \prime}$ \\
\hline Oscillatoria acuminata PCC6304 & 3 & $+a^{\prime}$ & $+c$ & $+{ }^{d}$ & - & + & - & $+\mathrm{g}$ & + & $+\mathrm{j}^{\prime \prime}$ \\
\hline Oscillatoria nigroviridis PCC7112 & 4 & $+a^{\prime}$ & $++^{\mathrm{c}}$ & + & - & - & $+^{\mathrm{f}}$ & $+\mathrm{g}$ & + & $+\mathrm{j}^{\prime \prime}$ \\
\hline Pseudanabaena sp. PCC7367 & 4 & + & + & + & - & + & - & $+\mathrm{g}$ & + & + \\
\hline Trichodesmium erythraeum ISM101 & 4 & $3^{\mathrm{an}}$ & - & + & - & - & - & $+\mathrm{g}$ & + & $+j^{\prime \prime}$ \\
\hline Chroococcidiopsis thermalis PCC7203 & 5 & + & + & $+{ }^{d}$ & - & $+\mathrm{e}^{\prime \prime}$ & - & $+\mathrm{g}$ & 2 & $+\mathrm{j}^{\prime \prime}$ \\
\hline Pleurocapsa sp. PCC7327 & 5 & + & $+\mathrm{c}^{\prime}$ & + & $+\mathrm{e}^{\prime}$ & $+\mathrm{e}$ & - & $+\mathrm{g}$ & $+{ }^{i}$ & $+\mathrm{j}^{\prime \prime}$ \\
\hline Stanieria cyanosphaera PCC7437 & 4 & + & + & + & $+e^{\prime}$ & $+\mathrm{e}^{\prime}$ & - & $+\mathrm{g}$ & $+\mathrm{i}$ & $+j^{\prime \prime}$ \\
\hline Prochlorococcus marinus AS9601 & 3 & $++^{b}$ & $+c^{\prime \prime \prime}$ & $+{ }^{d}$ & - & - & - & $+g^{\prime}$ & - & - \\
\hline Prochlorococcus marinus MIT9211 & 2 & $++^{b}$ & $+c^{\prime \prime \prime}$ & - & - & - & - & $+g^{\prime}$ & + & - \\
\hline Prochlorococcus marinus MIT9215 & 2 & $+{ }^{b}$ & $+\mathrm{c}^{\prime \prime \prime}$ & $?$ & - & - & - & $+\mathrm{g}^{\prime}$ & - & - \\
\hline Prochlorococcus marinus MIT9301 & 3 & $+\mathrm{b}$ & $+\mathrm{c}^{\prime \prime \prime}$ & $+d$ & - & - & - & $+g^{\prime}$ & - & - \\
\hline Prochlorococcus marinus MIT9303 & 1 & $++^{b}$ & - & - & - & - & - & $+\mathrm{g}^{\prime}$ & - & - \\
\hline Prochlorococcus marinus MIT9312 & 3 & $+{ }^{b}$ & $+\mathrm{c}^{\prime \prime \prime}$ & $+{ }^{d}$ & - & - & - & $+g^{\prime}$ & - & - \\
\hline Prochlorococcus marinus MIT9313 & 1 & $++^{b}$ & - & - & - & - & - & $+g^{\prime}$ & - & - \\
\hline Prochlorococcus marinus MIT9515 & 2 & $+{ }^{b}$ & + & - & - & - & - & $+\mathrm{g}^{\prime}$ & - & - \\
\hline Prochlorococcus marinus NATL1A & 3 & $++^{b}$ & + & - & - & - & - & $+\mathrm{g}^{\prime}$ & - & - \\
\hline Prochlorococcus marinus NATL2A & 3 & $++^{b}$ & + & - & - & - & - & $+g^{\prime}$ & - & - \\
\hline Prochlorococcus marinus SS120 & 2 & $++^{b}$ & + & - & - & - & - & $+g^{\prime}$ & + & - \\
\hline Prochlorococcus marinus MED4 & 3 & $+\mathrm{b}$ & $+\mathrm{c}^{\prime \prime}$ & $+{ }^{d}$ & - & - & - & $+g^{\prime}$ & - & - \\
\hline
\end{tabular}

The nine fed genes are designated as follows in Synechocystis: fed1 (ss10020) [5], fed 2 (sll1382), fed3 (slr1828), fed4 (slr0150), fed5 (slr0148), fed6 (ss12559), fed7 (sl10662), fed8 (ssr3184) and fed9 (s1r2059). The presence or absence in cyanobacteria of the Synechocystis orthologous fed genes is indicated by + , along the indicated numbers, or - , respectively. The superscript letters indicate those fed genes located in well-conserved genome organization contexts, which are depicted in Figure 1. $\sum$ indicates the total number of plant-like ferredoxin genes. 
Figure 1. Conserved genomic organization around the ferredoxin genes of the cyanobacterial genomes.

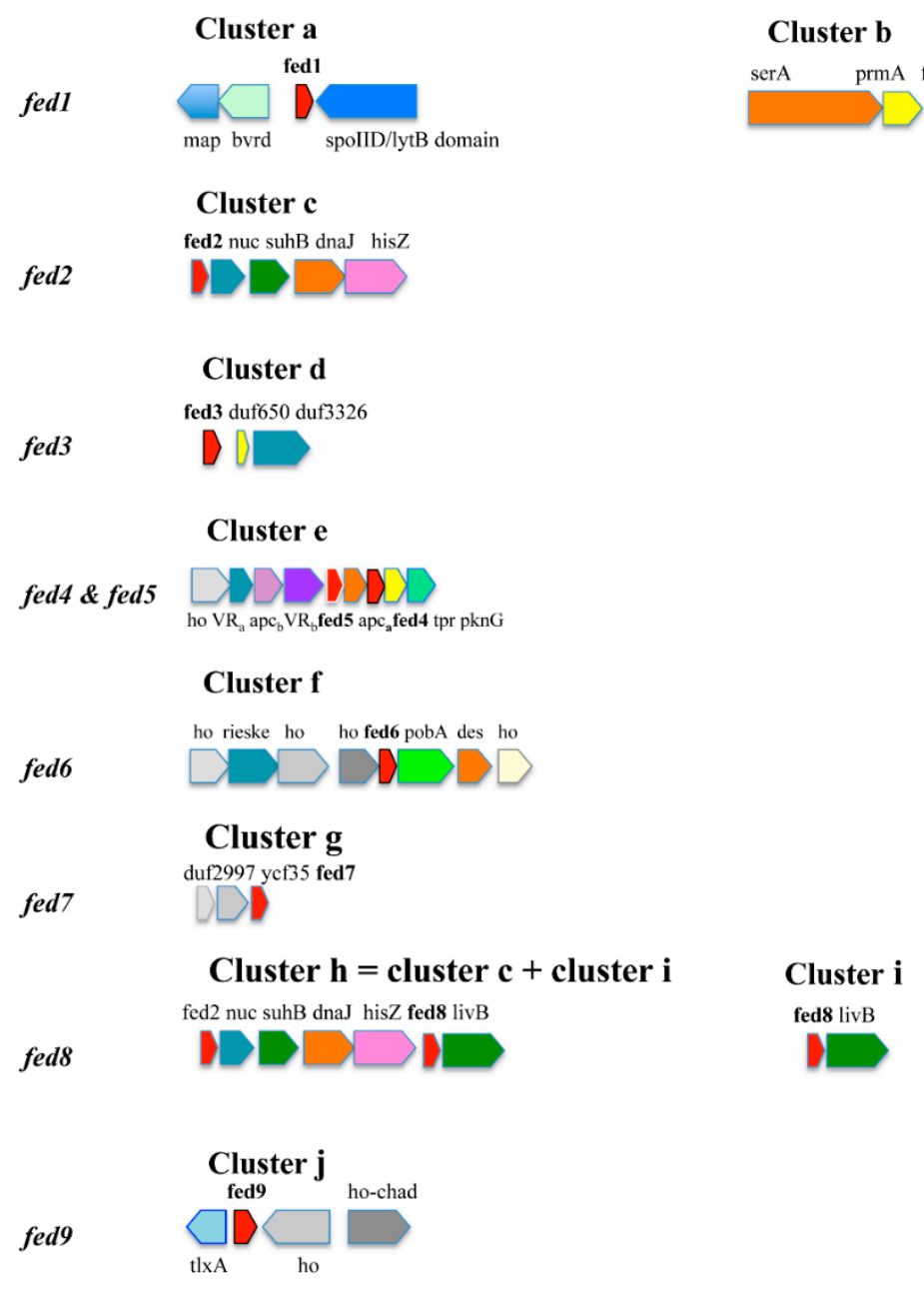

The genes are represented by boxes pointing in the direction of their transcription. Hypothetical genes are indicated as "ho". Cluster a = methionine aminopeptidase (map); putative biliverdin reductase (bvdR); fed1; spoIID/lytB domain-containing protein. Cluster $\mathbf{a}^{\prime}=$ Cluster a with no map gene. Cluster $\mathbf{b}=$ D-3-phosphoglycerate dehydrogenase (serA), ribosomal protein L11 methyltransferase (prmA), fed1. Cluster $\mathbf{c}=$ fed2; hypothetical nuclease (nuc); inositol-1-monophosphatase (suhB); heat shock protein DnaJ domain-containing protein (dnaJ); ATP phosphoribosyl-transferase regulatory subunit (hisZ). Cluster $\mathbf{c}^{\prime}=$ Cluster $\mathbf{c}$ with no nuc gene. Cluster $\mathbf{d}=$ fed3; conserved hypothetical protein DUF650 (duf650); conserved hypothetical protein DUF3326 (duf3326). Cluster e = hypothetical (ho); 4-vinyl reductase-like protein $\left(4 \mathrm{VR}_{\mathrm{a}}\right)$; protein harboring homology with allophycocyanin beta subunit (apcb); 4-vinyl reductase $(4 \mathrm{VR} b)$; fed4; protein similar to allophycocyanin alpha subunit $\left(\mathrm{apc}_{\mathrm{a}}\right)$; fed5; TPR domain containing protein (TPR). Cluster $\mathbf{e}^{\mathbf{\prime}}=$ Cluster $\mathbf{e}+$ threonine protein kinase (pknG). Cluster $\mathbf{e}^{\prime \prime}=$ Cluster $\mathbf{e}^{\prime}$ without fed4.

Cluster $\mathbf{e}^{*}=$ Cluster $\mathbf{e}$ lacking fed4. Cluster $\mathbf{f}=$ hypothetical protein (ho); ring-hydroxylating dioxygenase (2Fe-2S) large terminal subunit (rieske); hypothetical protein (ho); hypothetical protein (ho); fed6; ring-hydroxylating dioxygenase $(2 \mathrm{Fe}-2 \mathrm{~S})$ domain-containing protein phenoxybenzoate dioxygenase subunit (pobA); sterol desaturase (des); hypothetical protein (ho). Cluster $\mathbf{f}^{\prime}=$ Cluster $\mathbf{f}$ with two hypothetical protein-encoding genes (ho) located between fed6 and pobA. Cluster g = DUF2997 
domain-containing hypothetical protein (duf2997); DUF1257 domain-containing hypothetical protein (ycf 35); fed7. Cluster $\mathbf{h}=$ Cluster $\mathbf{c}+$ Cluster i. Cluster $\mathbf{h}^{\prime}=$ Cluster $\mathbf{c}$ lacking fed2; nuc and suhB + Cluster i. Cluster $\mathbf{h}^{\prime \prime}=$ Cluster $\mathbf{c}$ missing fed 2 and nuc + Cluster $\mathbf{i}$. Cluster $\mathbf{i}=$ fed8; ABC-type branched-chain amino acid transport systems; ATPase component (livB). Cluster $\mathbf{j}=$ thiol-disulfide interchange protein (TxlA); Fed9; hypothetical protein (ho); CHAD domain-containing protein (chad). Cluster $\mathbf{j} *=\mathbf{j}$ missing ho. Cluster $\mathbf{j}^{\prime}=$ Cluster $\mathbf{j}$ without chad. Cluster $\mathbf{j}^{\prime \prime}=$ Cluster $\mathbf{j}$ lacking both ho and chad.

\section{The Synechocystis Ferredoxins Genes Are Differently Regulated by Trophic Conditions}

The influence of environmental conditions on the expression of the ferredoxin genes was analyzed by northern blot and/or DNA microarrays experiments, as well as transcriptional fusion to a reporter gene in the case of the $f e d 1$ gene (ss10020, also named petF). The fedl monocistronic transcripts, which are abundant in standard photoautotrophic conditions [9], in agreement with the high content of the Fed 1 protein [10], become scarce after a 15-min shift to darkness. They reappeared rapidly (in $5 \mathrm{~min}$ ) and strongly after re-illumination in a process requiring de novo transcription and active photosynthesis, similarly to what occurs in plants [11]. In Synechocystis, this regulation occurs, at least in part, at the level of the complex promoter, which possesses several light-responsive elements promoting strong light induction [11]. The expression of the $f e d I$ gene is also positively regulated by carbon $\left(\mathrm{NaHCO}_{3}\right)$ availability [11], under the control of $\mathrm{NdhR}$ [11], a key regulator of carbon assimilation [12]. Furthermore, fedl is negatively regulated by hydrogen peroxide $\left(\mathrm{H}_{2} \mathrm{O}_{2}\right)$, cadmium, iron starvation the photosynthetic inhibitors, DCMU (3-(3,4-dichlorophenyl)-1,1-dimethylurea) and DBMIB (2,5-dibromo-3-methyl-6-isopropyl-p-benzoquinone), selenate, selenite and zinc (Table 2).

Table 2. Regulation of the Synechocystis ferredoxin genes in response to environmental challenges.

\begin{tabular}{|c|c|c|}
\hline Name & $\begin{array}{l}\text { Conditions Triggering Upregulation } \\
\text { of the Fed Genes }\end{array}$ & $\begin{array}{l}\text { Conditions Triggering Downregulation } \\
\text { of the Fed Genes }\end{array}$ \\
\hline fedl & Light $[9,11] ; \mathrm{NaHCO}_{3}[11]$ & $\begin{array}{l}\text { Darkness [9]; } \mathrm{Cd}, \mathrm{LFe}, \mathrm{H}_{2} \mathrm{O}_{2}[11,13] ; \mathrm{Na}_{2} \mathrm{SeO}_{3}, \mathrm{Na}_{2} \mathrm{SeO}_{4}[11] ; \\
\mathrm{HZn} \text { [13]; DCMU, DBMIB, LiC, } \mathrm{HT}^{\circ}, \mathrm{SS} \text { [14] }\end{array}$ \\
\hline fed 2 & $\mathrm{Cd}, \mathrm{H}_{2} \mathrm{O}_{2}, \mathrm{HZn}$ [13]; HL, BL, UV, SS [14] & Gle [9]; $\mathrm{Na}_{2} \mathrm{SeO}_{4}[11] ; \mathrm{LiC}[14]$ \\
\hline fed3 & $\mathrm{BL} *[14]$ & $\mathrm{Cd}[13] ; \mathrm{H}_{2} \mathrm{O}_{2}[13,14] ; \mathrm{LiC}[14]$ \\
\hline fed4 & LL [9]; $\mathrm{H}_{2} \mathrm{O}_{2}[13]$ & Cd, LFe, HZn [13]; HL, DCMU, LiC, SS [14] \\
\hline fed5 & LL [9]; $\mathrm{H}_{2} \mathrm{O}_{2}[13]$ & Cd, LFe, HZn [13]; HL, DCMU, LiC, SS [14] \\
\hline fed6 & $\mathrm{BL}[14]$ & \\
\hline fed7 & LFe [13]; HL [14] LiC [15] & $\mathrm{H}_{2} \mathrm{O}_{2}[11,13] ; \mathrm{Cd}, \mathrm{HFe}[13]$ \\
\hline fed 8 & $\mathrm{Cd}[11] ; \mathrm{HL}, \mathrm{LiC}[14]$ & $\mathrm{H}_{2} \mathrm{O}_{2}, \mathrm{LFe}[14]$ \\
\hline fed 9 & $\mathrm{HL}, \mathrm{HT}^{\circ}[14]$ & \\
\hline
\end{tabular}

Note: BL, blue light; $\mathrm{BL}^{*}$, blue light (one out of the six time points); $\mathrm{Cd}$, cadmium; DCMU, (3-(3,4-dichlorophenyl)-1,1-dimethylurea); DBMIB, 2,5-dibromo-3-methyl-6-isopropyl-p-benzoquinone; Glc, glucose; $\mathrm{H}_{2} \mathrm{O}_{2}$, hydrogen peroxide; $\mathrm{LiC}$, inorganic carbon limitation; $\mathrm{HFe}$, high iron; LFe, iron starvation; $\mathrm{HL}$, high light; LL, low light; SS, salt stress; $\mathrm{HT}^{\circ}$, high temperature; HZn, high zinc. fed 4 and fed 5 belong to the slr0144-slr0151 octacistronic operon, while $f e d 7$ belongs to the ss10060-ss11263-ssl0662 tricistronic operon.

In contrast to fedl, the other fed genes of Synechocystis are weakly expressed under standard photoautotrophic conditions $[9,11,13]$. These observations are consistent with the fact that their products 
were undetected in Synechocystis protein extracts, unlike Fed1 [10]. Similarly to fed1, the eight other fed2-9 genes are regulated by environmental conditions (Table 2).

\section{The Nine Synechocystis Ferredoxins Play a Crucial Role in Photoautotrophic Growth or Tolerance to Environmental Stresses}

To investigate the nine fed genes, we independently replaced each fed coding sequence (fed-CS) with a transcription terminator-less marker, $\mathrm{Km}^{\mathrm{r}}$, for antibiotic selection, while maintaining their DNA flanking regions (about $300 \mathrm{bp}$ ) to serve for homologous recombinations mediating targeted gene replacement upon transformation to Synechocystis [16]. The resulting deletion cassettes $\left(\Delta f e d 1:: \mathrm{Km}^{\mathrm{r}}\right.$, $\Delta f e d 2:: \mathrm{Km}^{\mathrm{r}}, \Delta f e d 3:: \mathrm{Km}^{\mathrm{r}}, \Delta f e d 4:: \mathrm{Km}^{\mathrm{r}}, \Delta f e d 5:: \mathrm{Km}^{\mathrm{r}}, \Delta f e d 2:: \mathrm{Km}^{\mathrm{r}}, \Delta f e d 3:: \mathrm{Km}^{\mathrm{r}}, \Delta f e d 4:: \mathrm{Km}^{\mathrm{r}}$ and $\left.\Delta f e d 9:: \mathrm{Km}^{\mathrm{r}}\right)$ were independently introduced by transformation in Synechocystis, which harbors about 10 chromosome copies per cell [16]. We verified through PCR and DNA-sequencing that the marker gene had been properly inserted in the Synechocystis chromosome, in place of the studied gene, and we assayed whether the segregation between wild-type (WT) and mutant $(\Delta f e d)$ chromosome copies was complete (the studied $f e d$ gene is dispensable to cell growth) or not (the studied gene is essential to cell viability).

The $\Delta f e d 1:: \mathrm{Km}^{\mathrm{r}} / \mathrm{fed} 1^{+}$mutant growing under photoautotrophic condition harbored both WT $\left(f e d 1^{+}\right)$ and mutant $\left(\Delta f e d 1:: \mathrm{Km}^{\mathrm{r}}\right)$ chromosomes, irrespective of the duration ( $\geq 100$ generations) and dose (up to $300 \mu \mathrm{g} \cdot \mathrm{mL}^{-1}$ ) of the $\mathrm{Km}^{\mathrm{r}}$ selection. This result showed that fedl is essential to the photoautotrophic growth of Synechocystis [9], as observed in the obligate photoautotroph cyanobacterium, Synechococcus PCC7942 [17]. The Synechocystis fed 1 gene was found to be also crucial in cells growing in the presence of glucose, which supports cell growth in the absence of photosynthesis [9].

Like $f e d 1$, the $f e d 2, f e d 3, f e d 6$ and $f e d 8$ genes appeared to be essential to the photoautotrophic growth of Synechocystis (Table 3).

Table 3. Characteristics of the ferredoxin-encoding genes in Synechocystis.

\begin{tabular}{ccccc}
\hline Name & Gene ID & $\begin{array}{c}\text { Type of Iron } \\
\text { Sulfur Center }\end{array}$ & $\begin{array}{c}\text { Importance for } \\
\text { Photo-Autotrophic Growth }\end{array}$ & Reference \\
\hline$f e d 1$ & ss10020 & {$[2 \mathrm{Fe}-2 \mathrm{~S}]$ plant-like } & Essential & {$[4,9]$} \\
$f e d 2$ & sl11382 & {$[2 \mathrm{Fe}-2 \mathrm{~S}]$ plant-like } & Essential & This study \\
$f e d 3$ & slr1828 & {$[2 \mathrm{Fe}-2 \mathrm{~S}]$ plant-like } & Essential & This study \\
$f e d 4$ & slr0150 & {$[2 \mathrm{Fe}-2 \mathrm{~S}]$ plant-like } & Dispensable & This study, $[4]$ \\
$f e d 5$ & slr0148 & {$[2 \mathrm{Fe}-2 \mathrm{~S}]$ adrenodoxin-like } & Dispensable & This study \\
$f e d 6$ & ss12559 & {$[2 \mathrm{Fe}-2 \mathrm{~S}]$ bacterial type } & Essential & This study \\
$f e d 7$ & sl10662 & {$[4 \mathrm{Fe}-4 \mathrm{~S}]$} & Dispensable & {$[15,18]$} \\
$f e d 8$ & ssr3184 & {$[3 \mathrm{Fe}-4 \mathrm{~S}][4 \mathrm{Fe}-4 \mathrm{~S}]$} & Essential & This study \\
$f e d 9$ & slr2059 & {$[4 \mathrm{Fe}-4 \mathrm{~S}][4 \mathrm{Fe}-4 \mathrm{~S}]$} & Dispensable & This study \\
\hline
\end{tabular}


The cells depleted of either Fed3 or Fed8 were killed by a prolonged exposure to Km and could not be further studied, whereas the Fed2-depleted cells $\left(\Delta f e d 2:: \mathrm{Km}^{\mathrm{r}} / f e d 2^{+}\right)$appeared to display an increased size as compared to WT or Fed1-depleted cells (Figure 2).

Figure 2. Typical morphology of Synechocystis wild-type (WT) and mutant cells depleted in the essential plant-like ferredoxins, Fed1 $\left(\Delta f e d 1:: \mathrm{Km}^{\mathrm{r}} / f e d 1^{+}\right)$or Fed2 $\left(\Delta f e d 2:: \mathrm{Km}^{\mathrm{r}} / f e d 2^{+}\right)$.

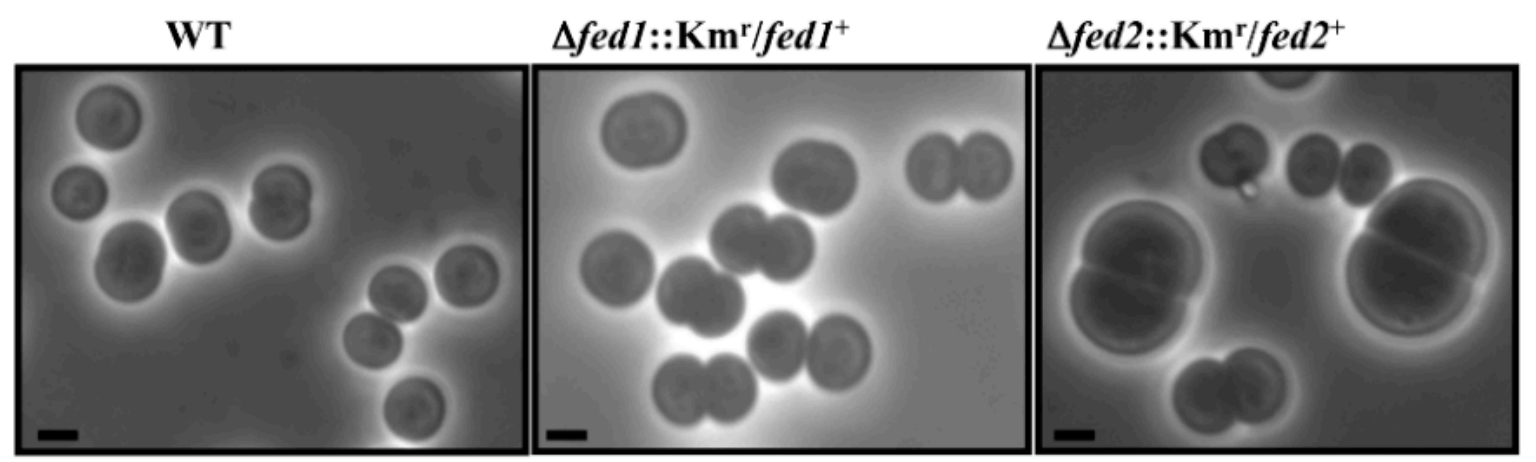

Note: Scale bar $=1 \mu \mathrm{m}$.

The four fed mutants, $\Delta f e d 4:: \mathrm{Km}^{\mathrm{r}}, \Delta f e d 5:: \mathrm{Km}^{\mathrm{r}}, \Delta f e d 7:: \mathrm{Km}^{\mathrm{r}}$ and $\Delta f e d 9:: \mathrm{Km}^{\mathrm{r}}$, retained no WT chromosome copies and grew healthily in photoautotrophic conditions. These findings indicate that the $f e d 4, f e d 5, f e d 7$ and $f e d 9$ genes are dispensable for Synechocystis growth, in agreement with previous reports on fed4 [4] and fed7 [15,18]. The complete absence of WT chromosomes in each mutant was also verified in cultures subsequently grown for about 100 generations in the absence of the Km antibiotic to stop counter-selecting the propagation of possibly remaining wild-type (WT) chromosome copies, prior to the PCR assays. The absence of WT chromosome copies confirmed that the fed4, fed5, fed7 and fed 9 genes are dispensable for the viability of Synechocystis (Table 3).

Fed7 and Fed9 Ferredoxins Plays a Prominent Role in the Tolerance to Oxidative and Metal Stresses, and the [2Fe-2S] Center of Fed7 Is Required for the Tolerance to Iron Starvation

As the mutants with $\mathrm{fed} 4, \mathrm{fed} 5, \mathrm{fed} 7$ or $\mathrm{fed} 9$ deleted grow well in standard photoautotrophic conditions, it was possible to investigate their tolerance to environmental stresses. In search of ferredoxin selectivity, we found that the absence of Fed7 or Fed9, but neither Fed4 nor Fed5, decreases the tolerance to oxidative and metal stresses (Figure 3). Furthermore, only Fed7 appeared to be involved in the protection against salt stress (Figure 3 ). 
Figure 3. Influence of the dispensable ferredoxins on the tolerance of Synechocystis to various environmental stresses.

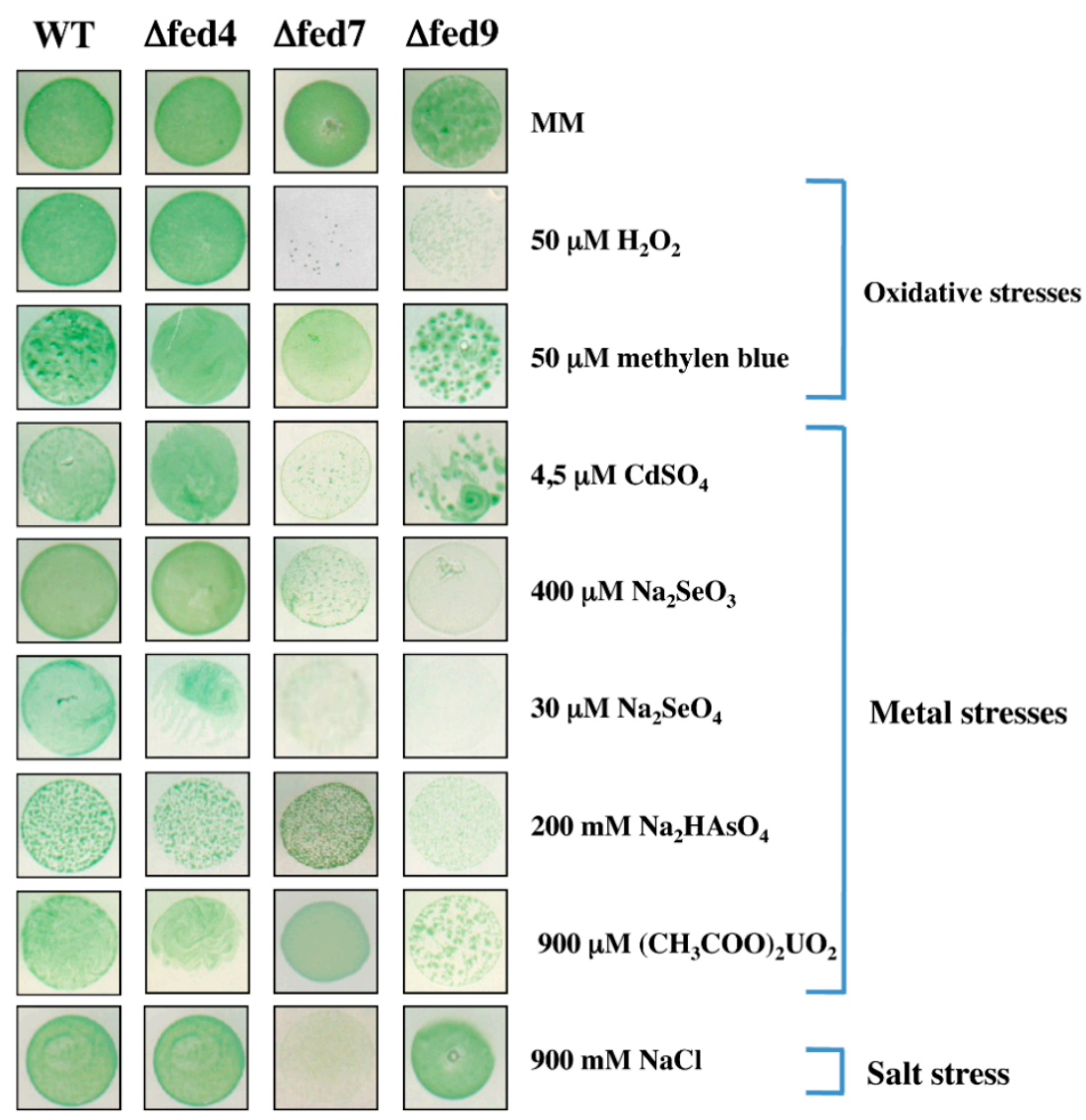

Ten-microliter aliquots of exponentially growing cells $\left(2.5 \times 10^{7}\right.$ cells $\left.\cdot \mathrm{mL}^{-1}\right)$ of the strains WT (wild-type), $\Delta f e d 4$ (fed 4 null mutant), $\Delta f e d 7$ ( $f e d 7$ null mutant) and $\Delta f e d 9$ (fed 9 null mutant) were spotted onto solid mineral medium (MM) with or without the indicated concentration of the tested agents. The plates were subsequently incubated for 4-5 days in standard photoautotrophic conditions at $30^{\circ} \mathrm{C}$, prior to image acquisition. As it is indistinguishable from that of $\Delta f e d 4$, the phenotype of the $\Delta f e d 5$ mutant is not shown. These experiments were performed at least three times.

Because $f e d 7$ appeared to be induced by iron starvation (Table 2), we anticipated that Fed 7 is required for protection against iron limitation. Indeed, the $\Delta f e d 7:: \mathrm{Km}^{\mathrm{r}}$ null mutant appeared to be susceptible to iron limitation, and this phenotype could be rescued by plasmid complementation, as follows. The fed7 protein coding sequence (Table 1) was cloned into the pFC1 plasmid, which replicates autonomously in Synechocystis at the same copy number as the polyploid chromosome and expresses the studied genes proportionally to the growth temperature [8]. As expected, the moderate production of Fed7 (driven by the pFed7 plasmid) in cells incubated at $34{ }^{\circ} \mathrm{C}$ rescued the otherwise low tolerance to iron limitation of the $\Delta f e d 7:: \mathrm{Km}^{\mathrm{r}}$ mutant back to the WT level (Figure 4). Using the same strategy, we found that the cysteine to serine substitution at position 100 in the Fed7 amino-acid sequence did not impair the rescue complementation (compare the strains $\Delta f e d 7$ with or without the plasmids pFed7 or pFed $7 \mathrm{C} 100 \mathrm{~s}$ ). By contrast, the triple mutation of cysteines 53, 56 and 59, which coordinates the [2Fe2S] center of Fed7 (together with C96), abolished the complementation (compare the strains $\Delta f e d 7$ with or without the

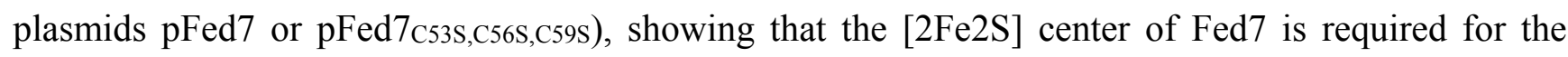


tolerance to iron starvation. These data show that Fed7 operates in tolerance of iron limitation, likely by constituting a redox-responsive element.

Figure 4. Influence of Fed7 and its [2Fe-2S] center on the tolerance of Synechocystis to iron limitation.

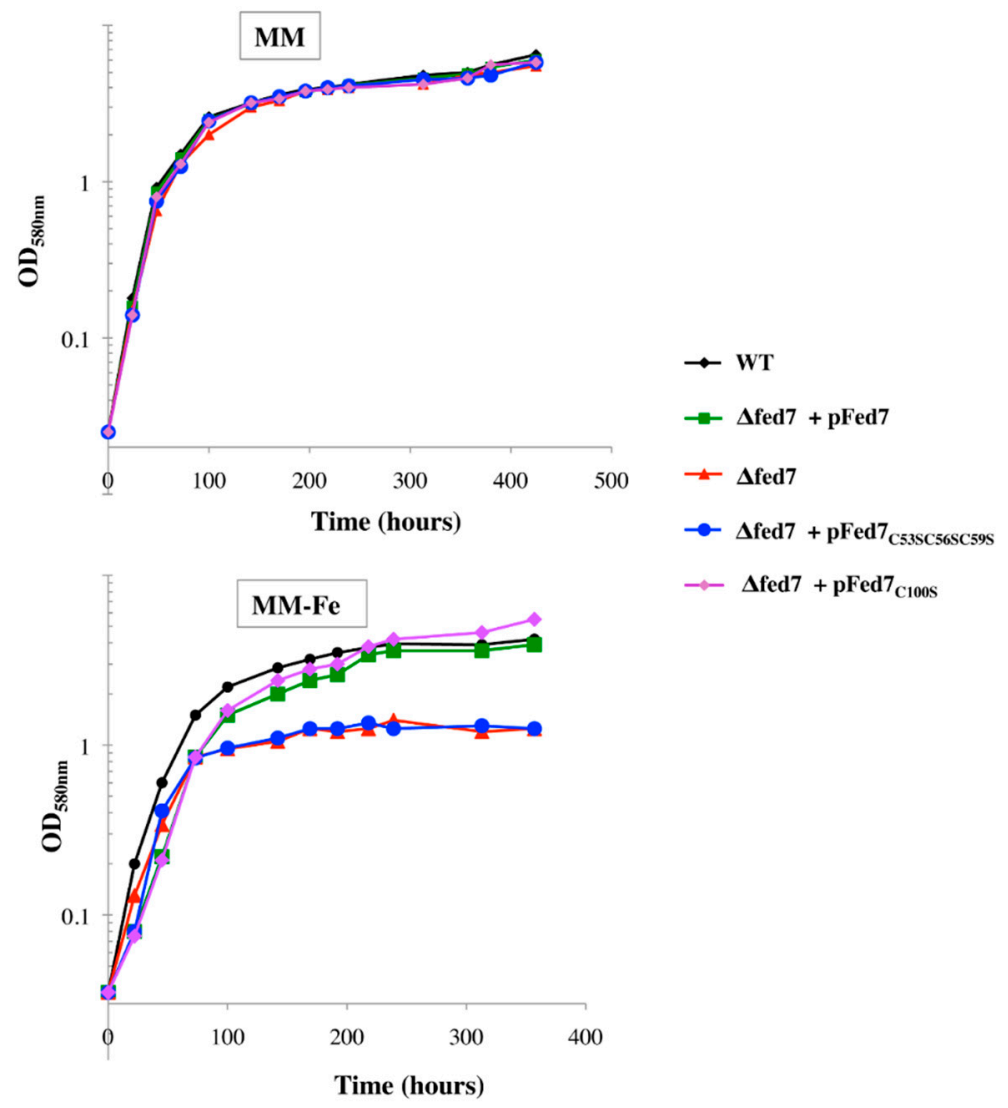

Typical growth of WT cells (black symbols) and mutant $\Delta \mathrm{fed} 7$ (red triangles), $\Delta \mathrm{fed} 7+\mathrm{pFed} 7$ (green

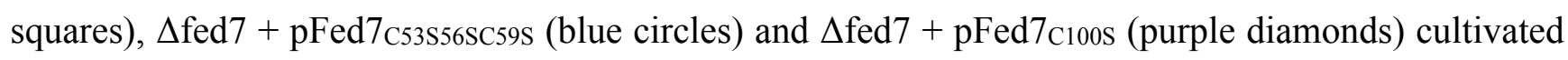
for the indicated durations in standard liquid mineral medium (MM, which contains $17 \mu \mathrm{M}$ Fe provided as ferric ammonium citrate) or in iron-limited medium (MM lacking ferric ammonium citrate, which contains only trace amounts of $\mathrm{Fe}$ ) are shown. All experiments were performed at least three times at $34{ }^{\circ} \mathrm{C}$ to allow moderate expression of the various $\mathrm{fed} 7$ alleles from the replicating plasmid $\mathrm{pFC} 1$ of the fed7 (see above).

\section{Analysis of the Selectivity/Redundancy of Ferredoxins: Identification of Fed-Interacting Proteins}

To identify proteins that can physically interact with one or several Feds, we used the bacterial adenylate cyclase two-hybrid (BACTH) system [19], exactly as we described [18,20,21]. The full-length coding sequences of the Feds and possible redox partners were translationally fused to the intrinsically-inactive adenylate cyclase domains of the replication-compatible BACTH reporter plasmids, pKT25 and pUT18. The resulting pUT18 and pKT25 derivatives were doubly-transformed to the E. coli reporter strain, DHM1, to search for protein-protein interaction that reconstituted adenylate cyclase, which turned on $\beta$-galactosidase. Several of these Fed-partner interactions were verified through the identification of interaction-disruptive mutations in each protein partner (Table 4). 
Table 4. Identification and analysis of Fed-interacting proteins with the bacterial adenylate cyclase two-hybrid (BACTH) system.

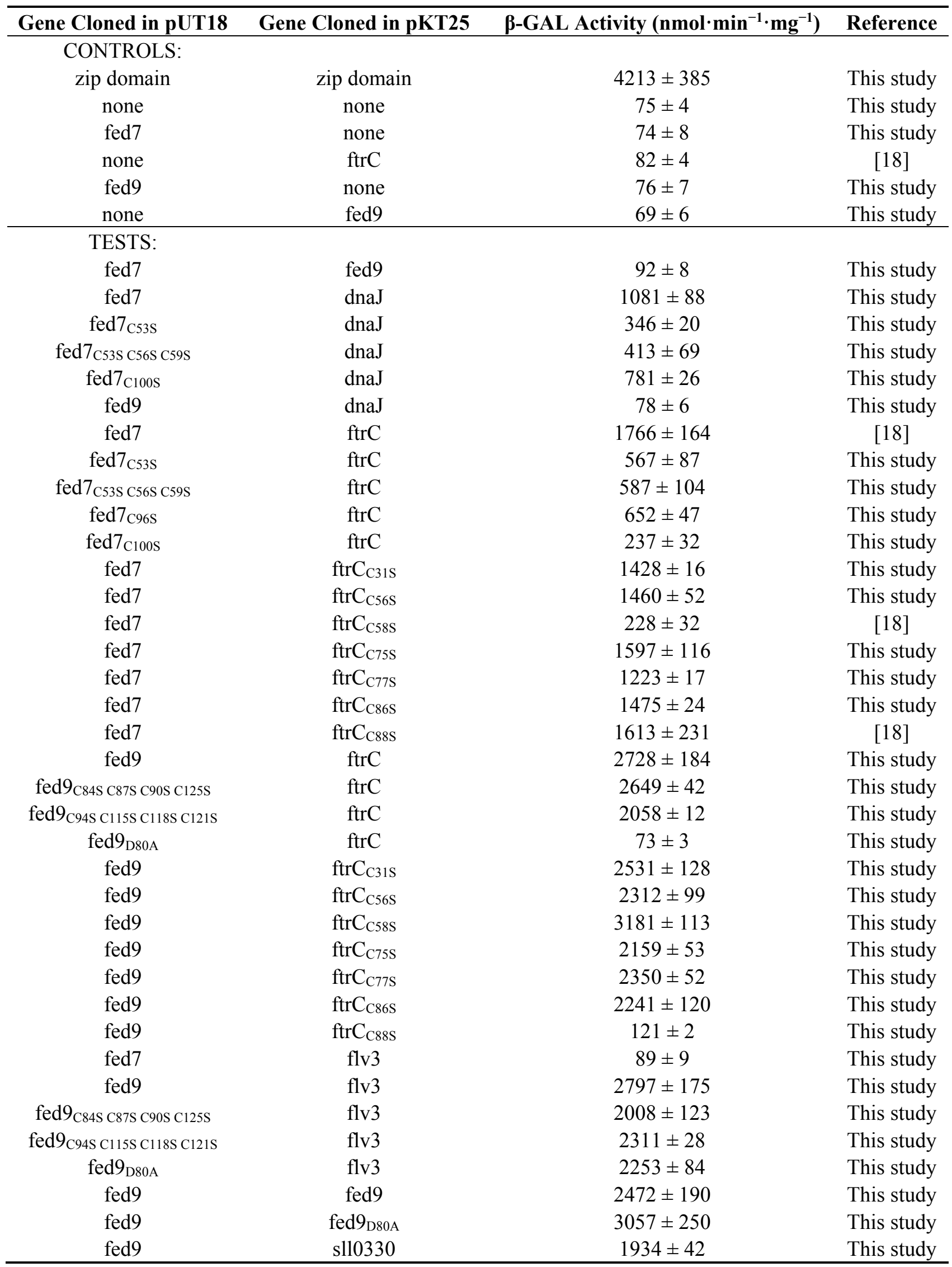


The occurrence of physical interactions between the Feds and their partner proteins produced from the replication compatible pUT18 and pKT25 BACTH reporter plasmids co-transformed to E. coli was ascertained by measuring the $\beta$-galactosidase activity ( $1 \beta$-Gal unit corresponds to the hydrolysis of $1 \mathrm{nmol}$ of $O$-nitrophenyl- $\beta$-D-galactopyranoside; $\mathrm{min}^{-1} \cdot \mathrm{mg}^{-1}$ of protein). The numbers are the mean value \pm standard deviations of six assays (three measurements performed on two different cell extracts). The plasmids with or without the zip insert served as positive and negative controls, respectively [19]. The nature and position of amino-acid substitutions are written in subscripts. The presumed redox-active cysteines are indicated with superscripted asterisks. The name of the Feds proteins partners are as follows: DnaJ-domain-containing protein, sll1384; Flv3 (flavodiiron protein 3), sl10550; FTRc (ferredoxin-thioredoxin reductase catalytic chain), S110554.

\subsection{Fed1, Fed7 and Fed9 Belong to a Ferredoxin-Glutaredoxin-Thioredoxin Crosstalk Pathway Operating in Stress Resistance}

Using a combination of methods (two-hybrid, GST pull-down, western blotting, enzymatic assays and gene deletion and plasmid-rescue complementation in Synechocystis), we showed that Fed7 belongs to a complex redox pathway [18]. This pathway sequentially transfers the photosynthetic electrons to Fed1, FTRc (the ferredoxin-thioredoxin reductase catalytic chain), Fed7 and glutaredoxin 2. In addition, glutaredoxin 2 can also receive electrons from the NAD(P)H-thioredoxin reductase-glutaredoxin 1 pathway. The resulting crosstalk pathway plays a crucial role in the protection against hydrogen peroxide and selenate [18].

Similarly to Fed1 and Fed7, Fed9 appeared to interact with FTRc (Table 4). From this Fed9-FTRc interaction and the following lines of evidence, we propose that Fed1 and Fed9 interact with the same face of FTRc to reduce it, whereas both Fed7 and thioredoxin (Trx) interact with the other face of FTRc to be reduced by it (Figure 5). First, knowing that electrons are transferred from the most to the least electronegative proteins, it is worth noting that the approximate redox potentials are $-420 \mathrm{mV}$ for both Fed1 and Fed9; $-350 \mathrm{mV}$ for FTRc; $-400 \mathrm{mV}$ or $-150 \mathrm{mV}$ for the [4Fe-4S] or the [3Fe-4S] forms of Fed7; and $-270 \mathrm{mV}$ for Trx (thioredoxin). Second, it has been shown that Fed1 and Trx bind on opposite sites of the disc-shaped FTRc protein, to form the Fed1-FTRc-TrxA pathway, which transfers electrons in that order [2,22]. Third, the Fed9-FTRc interaction was abolished by the D80A mutation in Fed9 and by the C88S mutation in FTRc, which did not impair the FTRc-Fed7 interaction (Table 4). Fourth, the FtrC-Fed7 interaction was abolished by the C100S mutation in Fed7 and by the C58S mutation in FTRc, which did not alter the Fed9-FTRc interaction (Table 4). By analogy with the Fed1-FTRc-TrxA redox pathway [22], we propose that in the case of oxidative stress, the [4Fe4S] cluster of Fed7 is converted into a $[3 \mathrm{Fe} 4 \mathrm{~S}]$ center, thereby liberating the C56 cysteine that normally operates in the coordination of the $[4 \mathrm{Fe} 4 \mathrm{~S}]$ cluster. The liberated $\mathrm{C} 56$ cysteine forms a disulfide bridge with the $\mathrm{C} 100$ cysteine, thereby turning the $[3 \mathrm{Fe} 4 \mathrm{~S}]$ form of Fed7 into a TrxA-like protein (Figure 5). 
Figure 5. Scheme representating the possible Fed1/Fed9-FtrC-TrxA/Fed7 interactions.

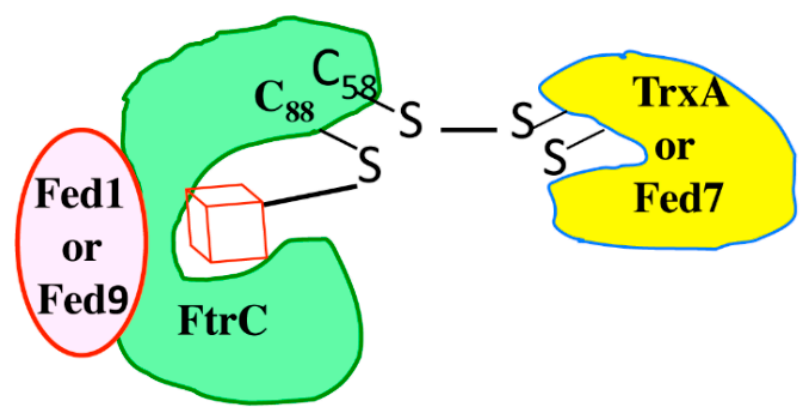

The FtrC protein and its [4Fe-4S] center are represented by the green form and the red cube, respectively, while Fed1 (and Fed9) are represented by the red circle and TrxA (and Fed7) by the yellow form.

\subsection{Identification of Proteins Selectively Interacting with Either Fed7 or Fed9, but Not Both}

As a step towards the identification of selective functions of Fed7 or Fed9, we noticed that Fed7, but not Fed9, physically interacts with S111384, a DnaJ-like protein (Table 4), which is dispensable to cell life [23], like Fed7 [15,18]. Our finding is consistent with the occurrence in photosynthetic eukaryotes, such as Chlamydomonas reinhardtii, of a DnaJ-Fed composite protein comprising a DnaJ domain (similar to S111384) fused to a Fed domain (similar to Fed7, the closest homolog of this Fed domain in Synechocystis). Together, these data support the proposal that eukaryotic DnaJ-Fed composite proteins evolved from independent, but physically-interacting DnaJ-like and Fed7-like cyanobacterial proteins [15,24].

Also, interestingly, we found that Fed9, but not Fed7, physically interacts with S110550, a non-essential flavodiiron protein (Flv3), which operates in the $\mathrm{NAD}(\mathrm{P}) \mathrm{H}$-driven photoreduction of $\mathrm{O}_{2}$ to $\mathrm{H}_{2} \mathrm{O}$ [25].

\section{Conclusions}

It is important to analyze the selectivity/redundancy of ferredoxins in cyanobacteria, because these enzymes play crucial roles in the growth and/or tolerance to environmental stresses of these fascinating organisms, which produce a large part of the oxygen and biomass for the food chain and also have high biotechnological interest. So far, most of what we know concerning cyanobacterial ferredoxins came from the analysis of the nine ferredoxins of the model strain, Synechocystis PCC6803, which are highly conserved in cyanobacteria. However, it is important to prolong and extend those studies by analyzing the ferredoxins of other cyanobacteria that colonize different biotopes (marine waters, desert soils) or perform processes not accomplished by Synechocystis (nitrogen fixation, multicellularity and differentiation of specialized cells, such as akinetes and/or heterocysts).

\section{Acknowledgments}

We thank Daniel Ladant (Pasteur Institute, Paris, France) for the gift of the bacterial two-hybrid system and several of our former students (Francis Domain, Benoit Marteyn, Martin Floutier and Omer Poyraz) for their participation at an initial stage of the work. This work was supported in part by the French scientific Programs "Toxicologie Nucléaire Environnementale" and "ANR Biosys06-134823: SULFIRHOM”. 


\section{Author Contributions}

Corinne Cassier-Chauvat and Franck Chauvat thoroughly analyzed of the literature and wrote of the paper. Both authors have read and approved the final manuscript.

\section{Conflicts of Interest}

The authors declare no conflict of interest.

\section{References}

1. Sticht, H.; Rosch, P. The structure of iron-sulfur proteins. Prog. Biophys. Mol. Biol. 1998, 70, 95-136.

2. Hanke, G.; Mulo, P. Plant type ferredoxins and ferredoxin-dependent metabolism. Plant Cell Environ. 2013, 36, 1071-1084.

3. Grinter, R.; Josts, I.; Zeth, K.; Roszak, A.W.; McCaughey, L.C.; Cogdell, R.J.; Milner, J.J.; Kelly, S.M.; Byron, O.; Walker, D. Structure of the atypical bacteriocin pectocin M2 implies a novel mechanism of protein uptake. Mol. Microbiol. 2014, 93, 234-246.

4. Gutekunst, K.; Chen, X.; Schreiber, K.; Kaspar, U.; Makam, S.; Appel, J. The bidirectional NiFe-hydrogenase in Synechocystis sp. PCC 6803 is reduced by flavodoxin and ferredoxin and is essential under mixotrophic, nitrate-limiting conditions. J. Biol. Chem. 2014, 289, 1930-1937.

5. Nakamura, Y.; Kaneko, T.; Hirosawa, M.; Miyajima, N.; Tabata, S. CyanoBase, a www database containing the complete nucleotide sequence of the genome of Synechocystis sp. strain PCC6803. Nucleic Acids Res. 1998, 26, 63-67.

6. Grigorieva, G.; Shestakov, S. Transformation in the cyanobacterium Synechocystis sp. 6803. FEMS Microbiol. Lett. 1982, 13, 367-370.

7. Marraccini, P.; Bulteau, S.; Cassierchauvat, C.; Mermetbouvier, P.; Chauvat, F. A Conjugative Plasmid Vector for Promoter Analysis in Several Cyanobacteria of the Genera Synechococcus and Synechocystis. Plant Mol. Biol. 1993, 23, 905-909.

8. Mermet-Bouvier, P.; Chauvat, F. A Conditional Expression Vector for the Cyanobacteria Synechocystis sp. Strains PCC6803 and PCC6714 or Synechococcus sp. Strains PCC7942 and PCC6301. Curr. Microbiol. 1994, 28, 145-148.

9. Poncelet, M.; Cassier-Chauvat, C.; Leschelle, X.; Bottin, H.; Chauvat, F. Targeted deletion and mutational analysis of the essential (2Fe-2S) plant-like ferredoxin in Synechocystis PCC6803 by plasmid shuffling. Mol. Microbiol. 1998, 28, 813-821.

10. Bottin, H.; Lagoutte, B. Ferredoxin and flavodoxin from the cyanobacterium Synechocystis sp. PCC 6803. Biochim. Biophys. Acta 1992, 1101, 48-56.

11. Mazouni, K.; Domain, F.; Chauvat, F.; Cassier-Chauvat, C. Expression and regulation of the crucial plant-like ferredoxin of cyanobacteria. Mol. Microbiol. 2003, 49, 1019-1029.

12. Figge, R.M.; Cassier-Chauvat, C.; Chauvat, F.; Cerff, R. Characterization and analysis of an $\mathrm{NAD}(\mathrm{P}) \mathrm{H}$ dehydrogenase transcriptional regulator critical for the survival of cyanobacteria facing inorganic carbon starvation and osmotic stress. Mol. Microbiol. 2001, 39, 455-468.

13. Houot, L.; Floutier, M.; Marteyn, B.; Michaut, M.; Picciocchi, A.; Legrain, P.; Aude, J.C.; Cassier-Chauvat, C.; Chauvat, F. Cadmium triggers an integrated reprogramming of the metabolism 
of Synechocystis PCC6803, under the control of the Slr1738 regulator. BMC Genomics 2007, 8, doi:10.1186/1471-2164-8-350.

14. Singh, A.K.; Elvitigala, T.; Cameron, J.C.; Ghosh, B.K.; Bhattacharyya-Pakrasi, M.; Pakrasi, H.B. Integrative analysis of large scale expression profiles reveals core transcriptional response and coordination between multiple cellular processes in a cyanobacterium. BMC Syst. Biol. 2010, 4, doi:10.1186/1752-0509-4-105.

15. Mustila, H.; Allahverdiyeva, Y.; Isojarvi, J.; Aro, E.M.; Eisenhut, M. The bacterial-type [4Fe-4S] ferredoxin 7 has a regulatory function under photooxidative stress conditions in the cyanobacterium Synechocystis sp. PCC 6803. Biochim. Biophys. Acta 2014, 1837, 1293-1304.

16. Labarre, J.; Chauvat, F.; Thuriaux, P. Insertional Mutagenesis by Random Cloning of Antibiotic-Resistance Genes into the Genome of the Cyanobacterium Synechocystis Strain Pcc-6803. J. Bacteriol. 1989, 171, 3449-3457.

17. Van der Plas, J.; de Groot, R.; Woortman, M.; Cremers, F.; Borrias, M.; van Arkel, G.; Weisbeek, P. Genes encoding ferredoxins from Anabaena sp. PCC 7937 and Synechococcus sp. PCC 7942: Structure and regulation. Photosynth. Res. 1988, 18, 179-204.

18. Marteyn, B.; Domain, F.; Legrain, P.; Chauvat, F.; Cassier-Chauvat, C. The thioredoxin reductase-glutaredoxins-ferredoxin crossroad pathway for selenate tolerance in Synechocystis PCC6803. Mol. Microbiol. 2009, 71, 520-532.

19. Karimova, G.; Pidoux, J.; Ullmann, A.; Ladant, D. A bacterial two-hybrid system based on a reconstituted signal transduction pathway. Proc. Natl. Acad. Sci. USA 1998, 95, 5752-5756.

20. Marbouty, M.; Saguez, C.; Cassier-Chauvat, C.; Chauvat, F. ZipN, an FtsA-like orchestrator of divisome assembly in the model cyanobacterium Synechocystis PCC6803. Mol. Microbiol. 2009, 74, 409-420.

21. Marteyn, B.; Sakr, S.; Farci, S.; Bedhomme, M.; Chardonnet, S.; Decottignies, P.; Lemaire, S.D.; Cassier-Chauvat, C.; Chauvat, F. The Synechocystis PCC6803 MerA-Like Enzyme Operates in the Reduction of Both Mercury and Uranium under the Control of the Glutaredoxin 1 Enzyme. J. Bacteriol. 2013, 195, 4138-4145.

22. Dai, S.; Schwendtmayer, C.; Schurmann, P.; Ramaswamy, S.; Eklund, H. Redox signaling in chloroplasts: Cleavage of disulfides by an iron-sulfur cluster. Science 2000, 287, 655-658.

23. Duppre, E.; Rupprecht, E.; Schneider, D. Specific and promiscuous functions of multiple DnaJ proteins in Synechocystis sp. PCC 6803. Microbiology 2011, 157, 1269-1278.

24. Petitjean, C.; Moreira, D.; Lopez-Garcia, P.; Brochier-Armanet, C. Horizontal gene transfer of a chloroplast DnaJ-Fer protein to Thaumarchaeota and the evolutionary history of the DnaK chaperone system in Archaea. BMC Evolut. Biol. 2012, 12, doi:10.1186/1471-2148-12-226.

25. Allahverdiyeva, Y.; Ermakova, M.; Eisenhut, M.; Zhang, P.; Richaud, P.; Hagemann, M.; Cournac, L.; Aro, E.M. Interplay between flavodiiron proteins and photorespiration in Synechocystis sp. PCC 6803. J. Biol. Chem. 2011, 286, 24007-24014.

(C) 2014 by the authors; licensee MDPI, Basel, Switzerland. This article is an open access article distributed under the terms and conditions of the Creative Commons Attribution license (http://creativecommons.org/licenses/by/4.0/). 